\title{
Strategic Competency Model of Researchers of Iran's Petroleum Research Centers
}

\author{
${ }^{1}$ Ahmad Farmahini Farahani, ${ }^{, 2}$ Fathollah Moztarzadeh, ${ }^{3}$ Mohsen Bahrami \\ ${ }^{1}$ Department of Management, Science \& Technology, Amirkabir University of Technology, Tehran, Iran \\ ${ }^{2}$ Faculty of Biomedical Engineering, Amirkabir University of Technology, Tehran, Iran \\ ${ }^{3}$ Faculty of Mechanical Engineering, Amirkabir University of Technology, Tehran, Iran \\ Email: ${ }^{1}$ Dr.Ahmad.Farmahini@gmail.com, ${ }^{2}$ moztarzadeh@aut.ac.ir, ${ }^{3}$ mbahrami@aut.ac.ir
}

Received: 29th October 2019, Accepted: 11th November 2019, Published: 31st December 2019

\begin{abstract}
Competencies provide a solid foundation for creating compatible performance standards. In order to create a new research culture and to overcome future challenges, research managers strongly need researchers that have strategic competencies in the oil industry to be present at a global level and to obtain technologies. In this paper, the subject of designing strategic competency models for researchers of industrial petroleum centers to be present at world scientific assemblies for future development has been studied. In this research, factors of competency are explained and detected using desk research and experts' opinions; then, competency factors are categorized and analyzed by employing predicting methods and then the competency model of researchers at petroleum research centers is presented. In the end, the practical model of measuring the mentioned competencies is provided to be used by the mentioned individuals and institutions.
\end{abstract}

\section{Keywords}

Competency, Researchers, Industrial Research Centers, Petroleum Industry, Model of Strategic Competencies

\section{Introduction}

Competencies provide a solid foundation for creating compatible performance standards. In order to create a new research culture and to overcome future challenges, research managers strongly need researchers that have strategic competencies in the oil industry to be present at a global level and to obtain technologies. Considering the global environment of petroleum business and future events, researchers' competencies are extremely important for future development. Presenting a model based on scientific and empirical foundations can be considered as one of the fundamental solutions that enables researchers to face events related to petroleum industry, in terms of global competitiveness [1].

Petroleum and in general energy industry, because of their international nature, are one of the main challenges and possible future crises in the world. Considering the competitors and consumption changes, especially in emerging industrial countries, we should turn to new paradigms to be able to be present in a highly competitive market and to create a competitive advantage. This subject is naturally considered as responsibilities and missions of the research field; but this field requires researchers with strategic competencies, high knowledge capacities and etc [2].

Achieving value-creation processes in the petroleum industry and creating a dynamic procedure requires a strategic shift in thinking and choosing purposeful strategies. To reach this place, we need policies in science and technology, different thinking and attitude and paying attention to creativity and innovation so that petroleum industry can be effectively present at an international level. In order to accomplish the goals of technology, study and research policies in petroleum industry, we inevitably need to improve the competencies of researchers at petroleum research centers (Department of Study and Management of Defense University, Production of science and technology, 2008)[3].

Most organizations manage their human resources the same way and maybe even implement same policies in the management of their human resources; meaning that they do not differentiate between their knowledge workers which can lead to various consequences in terms of job satisfaction, desire to quit, commitment and etc. Davenport says: "our first belief is that putting all the researchers in the same level can be a huge mistake."

All knowledge workers are not similar and they need to be categorized. Therefore, adopting an approach to categorize knowledge workers can help organizations identify the best method to manage, evaluate and improve their work. Various goals force researchers to use various approaches to categorize knowledge workers.

Competency models show an image of a developed human who has the necessary equipments to successfully carry out his given tasks and responsibilities. In fact, competency models define competencies that are required for a completely successful performance in a job, team work or in a part of an organization. Competency models usually consist of a list of competencies and behavioral indicators that express the competencies according to what is supposed to be seen in an organization [4].

Considering the mentioned subjects and in the first step, identifying researchers in petroleum industry research centers is an essential and fundamental issue, so that the petroleum industry can provide its future needs while being on the path of study and research.

On the other hand, to efficiently carry out these activities, workers in this field must have the necessary competencies for that level of knowledge workers. Considering the absence of a competency model for knowledge workers of the 
petroleum industry, often their recruitment, employment and promotion are not correctly done in career progression paths and this leads to disappointment and hopelessness of capable and competence workers. Thus, the main goal of this research is detecting the competencies required for researchers in petroleum industry research centers.

Therefore, the current study has been conducted with the aim of identifying and designing a competency model for researches and the method used in this study is case study and data analysis method. In this paper, we design a strategic competency model for researchers to meet the needs of petroleum industry in petroleum research centers.

\section{Materials and Methods/Methodology}

\section{Prospect of Human Resources of Iran's Petroleum Industry in 2025 Vision Plan}

In Iran's 2025 vision plan and in order to accomplish the great goals of the country's petroleum industry, Iran's petroleum industry, in addition to having a performance-based fair payment system, will have a proper balance in the supply and demand system of human resources and will be aware of the competitors in the international environment by employing professional and committed human workforce and by relying on the progression platform provided for individuals and the organization and also by counting on the rich Islamic-Iranian culture in a learning, creative and value-creating environment and also by supporting and employing monitoring systems, comprehensive HR data base and industry evaluation centers. In this vision plan, the petroleum industry will have excellent human assets that will be leaders in the field of Islamic ethics and modern professional knowledge and technology; they will be capable of doing activities at a global level and will be excellent in social responsibility and satisfying beneficiaries. In this vision, petroleum industry will have the higher share in the value added of products and will be well-known in the national and international environments [5].

According to this vision plan, the goals of petroleum industry's HR development have been specified. In one of these goals, scientism and meritocracy (general policies of the administrative system announced by the Supreme Leader) have been mentioned and based on this, the following items are talked about: the strategic need of disproportion between the education system and the industry's needs, the necessity to pay attention to and support research and academic centers that are powerful in the petroleum industry with the goal of convergence between industry and university, supporting affiliated or independent research and academic centers in order to meet the educational and research needs of the petroleum industry.

Goals of petroleum industry's HR in order to meet this strategic need are as following:

- HR development coordinated with the goals determined in the upstream documents of the country and industry in order to perform activities at a global level.

- Studying and investigating the knowledge gap, proficiency and perspectives of petroleum industry HR compared to competitors, in order to allocate the necessary resources for investment in HR education and research.

- Providing a comprehensive image of the quantitative and qualitative supply and demand of the workforce needed by petroleum industry and offering solutions to reduce the existing gap and also correcting the signals of the petroleum industry workforce market.

- Establishing, supporting and improving an evaluation center, in order to assess the quantity and quality of the workforce and consequently forming an identification, education and improvement system for the career progression path of the workers and replacement system.

- Studying and investigating the international workforce market to identify and recruit foreign workforce. - Creating a vertical alignment between HR strategies, policies and plans and its related affairs on the organization level and also creating horizontal alignment between the components and elements of HR management.

- Adjusting policies and executing efficient programs to maximize HR efficiency in the petroleum industry, in order to improve the performance of the organization.

Based on the above-mentioned goals, the following strategies are considered for HR development in petroleum industry scientific and research centers[6]:

1. Designing and establishing a management information center for HR education and research, in order to interact with universities and scientific centers.

2. Investigating and evaluating the education systems of top rival companies, so that we could employ their experiences in improving the existing education systems and procedures in the petroleum industry.

3. Precise determination of HR education and research needs, in order to meet the industry needs in employing methods such as forming workgroups consisting of people who are familiar with the industry's development needs, HR monitoring centers and similar items.

4. Increasing communication between industry and academic centers and professional institutes for accurate transmission of industry needs to these centers.

5. Recruiting new forces who have useful and efficient knowledge and experience and reforming the workforce pyramid towards a knowledge-based organization

6. Culturalization to get the support of senior managers for allocating the necessary resources to development projects; especially in recruiting expert and professional workforce as an investment in research and development HR

7. Preparing the groundwork for development of HR capabilities in research and development centers by employing methods such as modifying and reforming the required laws and regulations and carrying out the necessary follow-ups for their ratification and efficient execution. 
8. Paying extra attention to increasing the resources and legal authorities of The Research Institute of Petroleum Industry, Institute for International Energy Studies and The Petroleum University of Technology as three professional centers in conducting the necessary researches and educating the required human resource in the petroleum industry along with other universities and educational centers of the country.

9. Reforming and improving the maintenance systems with special attention to research and development centers, so that the knowledge workers of these units will have organizational commitment and adequate satisfaction and spend their useful working life in this field.

Importance of Researchers in Petroleum Industry Workforce

Researchers play a crucial role in the vision, goals and strategies for petroleum industry workforce and on the other hand, Iran's petroleum industry still has a special and decisive place in our country's economic, social and cultural development. With this vision and the importance of petroleum industry and also the future development of this industry which requires a special place for researchers, it seems that conducting studies and researches in this field can be helpful. Therefore and considering the importance of human workforce and competency in research centers, the need for explaining this concept can be considered as the reason for selecting this study topic [7].

For this purpose and to achieve a scientific and practical model, comprehensive studies have been conducted on this subject that can be briefly explained using key words as the following:

Public policies and science and technology policies

In this regard, studying Persian and English resources can be mentioned as one of the public policies and policies in science and technology. This paper explains the serious need to understand the policies related to petroleum industry. Also, this paper explains the importance of researchers in creating a research conceptual model which is a decisive element [8].

How does science evolve and grow?

This topic presents a clear discussion on the process of science production and helps the research understand this process and have a scientific view. A fundamental question to understand this point is how should we look at the future, so that we can be more accurate in future development? [6]

Some of the management competencies required by organizations from the perspective of the UN for the future. The word "competency" refers to a set of skills and behaviors that are directly related to successful performance in a job. Core competencies include skills, methods and behaviors that are considered important for the organization staff, regardless of their status and responsibilities. Management competencies include skills, methods and behaviors that are considered necessary for workers on management and supervision levels.

\begin{tabular}{|c|c|c|}
\hline Core Values & Integrity (Perfect Integrity) & $\begin{array}{l}\text { Definition of a researcher and efficient } \\
\text { management of researchers }\end{array}$ \\
\hline Integrity & Professionalism & Responsiveness \\
\hline Professionalism & Respecting Diversity & Competency or Leadership \\
\hline Diversity Capacity & Communications & Decision-making \\
\hline Communications & Teamwork & Role or Importance \\
\hline Teamwork & $\begin{array}{l}\text { Planning and } \\
\text { Organizing }\end{array}$ & Professional Growth \\
\hline Planning and Organizing & Responsiveness & Professional Knowledge \\
\hline Reliability & Customerism & Responsibility \\
\hline Creativity & Creativity & Personal Sufficiency \\
\hline Customerism & $\begin{array}{l}\text { Technological } \\
\text { Awareness }\end{array}$ & Self-Respect \\
\hline Commitment to Continues & Commitment to & Dignity \\
\hline Learning & Continues Learning & \\
\hline Technology Awareness & Vision & Coaching \\
\hline Management Competencies & Leadership & \\
\hline Leadership & Empowering Others & \\
\hline Vision & Performance & \\
\hline Empowering Others & Trust Building & \\
\hline Trust Building & $\begin{array}{l}\text { Judgment/Decision- } \\
\text { making }\end{array}$ & \\
\hline $\begin{array}{l}\text { Performance Management } \\
\text { Judgment/ Decision-Making }\end{array}$ & & \\
\hline
\end{tabular}

Table 1: Categorization of Management Competencies [9]

Innovation occurs when actions are justifiable by modern systems. Although the activities of researchers are basically unmanageable, pioneer organizations have gradually achieved structures, processes, systems, specific leading methods and appropriate cultural grounds for synergizing the efforts and thoughts of researchers; they have succeeded not only 
in employing thoughts and innovations, they also managed to do organizational knowledge-creation and its development. Efficient management of researchers require measures which will lead to qualitative and quantitative development of knowledge-learning capacities, efficient use of knowledge and knowledge development on the national level [10]

\section{Design Approach of a Competency Model for Researchers at Petroleum Industry Research Centers}

The most important competitive advantage of organizations in the $21^{\text {st }}$ century is their human assets. In other words, organizations will have competitive advantage that are able to recruit, nurture and keep the best knowledge workers in a competitive market. Competency methodologies are a new viewpoint for integrating this system[11]. Petroleum industry research centers, as knowledge-based organizations and for accomplishing research and study goals, strongly require capable knowledge workers. The aim of the present study is to identify and design a competency model for researchers. The method used is case study and data analysis method. Structural Equation Modelling (SEM) is carried out using LISREL software. The statistical population consists of petroleum industry research centers and the entire population has been studied. Based on the findings, the competency model is categorized based on "individual characteristics", "knowledge" and "skill"[12].

Competency models define competencies that are required for a completely successful performance in a job, team work or in a part of an organization. Competency models usually consist of a list of competencies and behavioral indicators that express the competencies according to what is supposed to be seen in an organization [4]. Nowadays, knowledge is considered as the most important asset of researchers in research centers. Thus, a new approach must be taken regarding knowledge workers. Change in the essence of organizational activities toward knowledge activities have increased the importance of knowledge management in organizations. In knowledge management, preserving and keeping researchers, creating knowledge capacity and its development play a decisive role in the organization's success and gaining a competitive advantage. Researchers are intellectual capitals of research centers and the most important assets of organizations. Therefore, keeping these people in the organization can be extremely important.

Activity and presence of each researcher is crucial to the research center. Because the organization spends huge amounts of money for these workers from recruitment to being hired and in the stages where they get familiar with the job and receive the necessary trainings. In addition to these costs being wasted and repeated for another person, the experiences earned by those people will be wasted as well. Also, some of these workers are crucial for the organization and their leave will disturb the activities. Thus, measures must be taken, so that organizations can create a strong emotional commitment in their workers and achieve a sustainable competitive advantage. In this regard, identifying the competencies of these workers are extremely important in activities of human resources.

\section{Theoretical Bases of Competency Model of Researchers}

In the field of scientific research, the concept of "competency" was first introduced by McCelland (1973) in a paper entitled "Measuring competency instead of intelligence". McCelland shed light on the concept of competency as behavioral and psychological traits that are related to successful consequences in work and life [13]. After that, Boyatzis (1982) published an article named "competent manager; a model for efficient performance" and expended the concept of competency in HR management and defined competency as a combination of motivation, characteristics, skills, social role, person's self-perception or his perception of the work [14]. This definition in the 1990s created a vast ground for discussion and different opinions about the concept of competency; and the concept has received attention from different approaches and multiple definitions have been presented in this field. During this time, researchers such as Ulrich, Brockbank, Young and Lake (1995), Blancer, Brosky and Deer (1996), Mirabile (1997), Armstrong (1999), Katano (2001), Bonder (2003) defined competency as knowledge[15], skill and other required behavioral traits. Trogman, Youlman, Marshal and Mai (1995) believe that competencies represent a combination of motivation, characteristics, self-perception, attitudes, values, knowledge content or cognitive-behavioral skills that can differentiate between mid-level and superior workers. Some pundits like Stabler \& Green (1999) defined competency as the written description of working habits and minimum measurable performance standards. McLagan (1996), Slonisky (1996), Mitrany, Dazyl and Fits (1992) defined competency as an underlying personal trait that is scientifically related to efficient performance in a job. It seems that one of the reasons for this obscurity in the concept of competency is related to individuals. Competency areas define activities in which the individual is competent; whereas individual-based competencies are a set of traits that enables a person to be competent in a specific field. In fact, competency areas are generally based on the occupation, whereas competencies are basically based on individuals. Anyway, the findings of Boyatzis (1982) and Spencer (1993) and also the findings of researchers with a more contingency approach, such as Stewart and Lyndsey (1997) and Chang (1997) confirm this theory that it is possible to create a list of abilities and competencies that are related to most job titles in all the levels of the organization [16]. Professional competencies consist of personal behaviors and traits such as skills, knowledge and attitudes. Since these factors are constantly and simultaneously interacting, therefore it is difficult to distinguish them from each other [17]. Professional competencies are divided into two categories of technical competencies and general competencies. Technical competencies include the professional and specific knowledge related to the job and is work-based (Agut \& Grau, 2002). Whereas general competencies refer to individual-based or worker-based competencies that can be effective in carrying out the job responsibilities and include personal characteristics such as motivation, attitude and personal traits (Cizel et al, 2007). Competency of an organization is an observable dimension that includes knowledge, skill, attitude and personal behaviors and also team processes and organizational qualifications that are related to high performance and will lead to 
gaining a sustainable competitive advantage. Competency of a human necessary for efficient performance is measureable. Competency can include knowledge, a single ability or skill, a personal trait or a combination of two or more of these characteristics. Competencies are the building blocks of work performance. Carrying out more responsibilities require the simultaneous or consecutive display of several competencies [16]. Competency is the ability to use or apply knowledge, skills, abilities, behaviors and personal traits that are decisive in successful conduction of work tasks, specific functions or successful performance in a specific role. Personal traits can be intellectual, cognitive, social, emotional, attitudinal, physical and mental that are essential in successful performance in a job [17].

Now, considering the unique role of researchers in petroleum industry research organizations, competency of researchers in these centers have been investigated.

\section{Research Methodology}

By investigating vast resources and researchers, we figured out that management competencies have a long history in the world which we discussed in the "literature" section. In Iran however, management competencies have been studied in two M.A. theses in recent years [18] and in the following years (2016), the management evaluation center of petroleum industry has been activated; although its foundations were established before in The National Iranian Oil Company and The National Petrochemical Company. Management competencies of project's managers were investigated for performance evaluation in 2017 in one of the operational managements, one of the research centers, and in one of the operational companies. HR management association has also categorized management competencies. Other industrial research centers in the country did not have any other activities besides the above-mentioned subjects; for instance, Energy Ministry research center has carried out appropriate activities regarding management competencies. Competency indices for researchers can be extracted up to a certain level by reviewing these researches; and in order to complete them, we used experts' opinions and prediction methods such as exploratory and Delphi methods. Data analysis was conducted using Structural Equation Modelling (SEM) by LISTEL software. Statistical population of the research consisted of researchers of petroleum industry research centers and the entire population were studied. In order to answer the research questions and considering the defined goals, a deep and thorough search was conducted into library and archive resources and also into the latest journals in the field. Considering the novelty and freshness of the research topic and the fact that no research has ever been done in Iran's research organizations, in this field, most of the studies in published papers and books were done on an international level and they have also considered the executive experiences of consulting firms. In order to ensure the research validity, we used the opinions and suggestions of the academic elite, supervisors of management development and experts and researchers of the field in data collection stages (deep interview), designing the initial model (Delphi panel) and conclusion. In designing the model of competencies, the achieved model was initially analyzed and overviewed using Delphi model. In the next step, 20 experts were interviewed and their statements were analyzed. In the next step and to ensure the validity of the questionnaire, 25 related experts from the researchers filled in the questionnaires and the initial validity calculations were confirmed; then the interview and test results were comparatively reviewed with the research literature and in the end, questionnaires were given to 80 researchers to express their opinions. Finally, the competency model was finalized with 6 components and 48 competencies. Based on the special form, the survey was conducted and the validity was confirmed using Cronbach's alpha. Also, the entire statistical population were investigated and the results were generalized to the entire researchers of petroleum industry using Morgan's formula. Investigating upstream documents of petroleum industry and employing models of designing management competencies by using scientific resources and experiences of operational and research organizations in the petroleum industry.

\section{Global Challenges and Competency Needs of a Researcher}

By reviewing the literature, 15 global challenges that researchers should keep in mind are as following. ([19],[20],[21]). The 15 global challenges provide a framework for evaluation of local and global image for humans. Challenges are dependent on each other; paying attention to one makes another one easier and the failure to take one into account makes another one more difficult. Discussion on these challenges, where one is more important than the other, is like arguing whether the neural system is more important or the respiratory system. In designing the questionnaire, the futuristic and developmental indices are adjusted based on global challenges. In these challenges, the subjects of science and technology, energy, information technology and decision-making capacity are mentioned, which play a direct role in strategic competencies of petroleum industry researchers. In the following, a diagram for the position of 15 global challenges is presented.

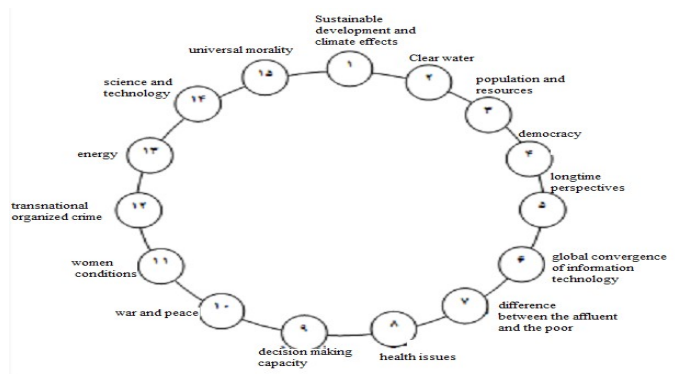

Figure 1: The Position of 15 Global Challenges [22] 
Reviewing Management Competency Models

A) Experiences of Iran oil industry operational organization

Based on literature review of management competency models and considering the organization's missions, values and strategies and by surveying senior managers of the organization, the evaluation criteria for management competencies in one of Iran's oil industry organizations are suggested as the following[19]:

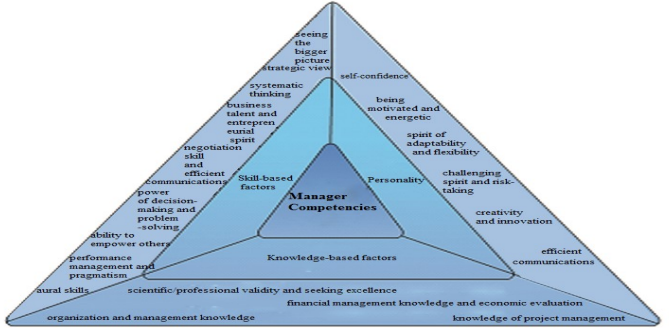

Figure 2: Competency Model of Managers with Personality, Skill-based and Knowledge-based Factors [19]

B) Competency model of middle and operational managers

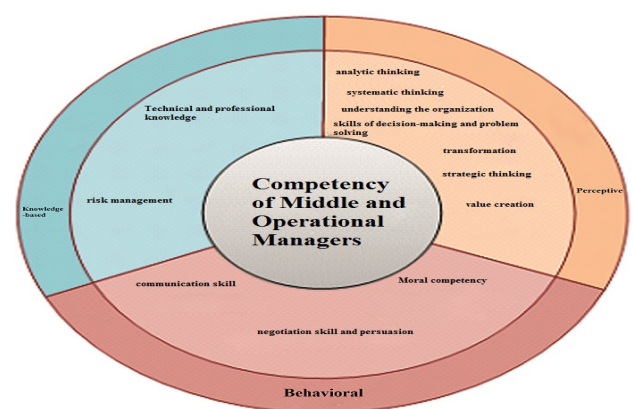

Figure 3: Competency Model of Middle and Operational Managers [20]

C) Competency model of top managers

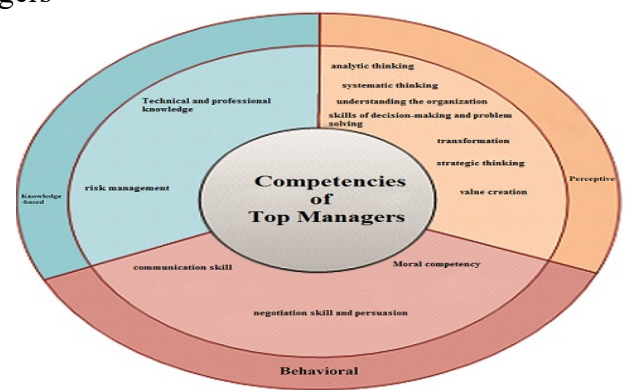

Figure 4: Competency Model of Top Managers [10]

Experience of a research organization in Iran's petroleum industry

In one of the research centers of country's petroleum industry, the model of management competencies is suggested as the following, based on the experts' opinions:

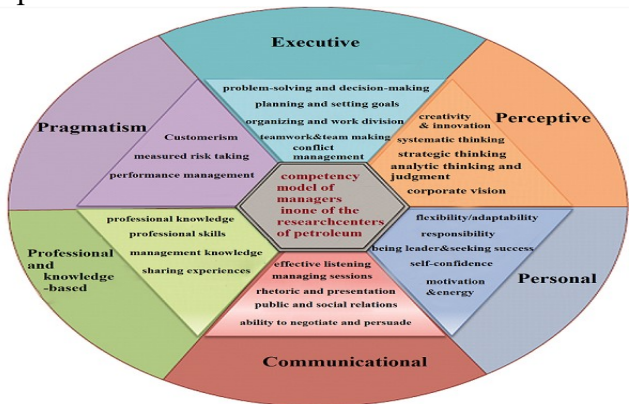

Figure 5: Competency Model of Managers in One of the Research Centers of Petroleum Industry

General Competency Model of Society for Human Resources Management

During the work progress and promotion of a human workforce, each HR specialist can significantly contribute to his/her organization's success. In this regard, Society for Human Resource Management has developed and evaluated multiple models to determine the behaviors that represent professionalism on different levels of an organization's 
human resources. Competency model of the Management Society is designed for HR experts that pay attention to competency improvement (ranging from new forces that have just started their work to senior managers). In other words, this competency model can act as a road map towards the HR's goals. This model is only applicable for developmental goals and selective decisions should not be made based on this model.

Competency is a set of capabilities that include knowledge, skill, abilities, self-knowledge, behaviors, ideology and emotions that when combined with appropriate roles, will help us achieve our goals. Competency is referred to as a performance pattern that logically influences the organization. Competency model of Society for HR Management is shown in this reports. The 9 main competencies are shown in this model; the part which is closer to researcher competencies has been noted in the questionnaire.

- Allocation of human workforce - Communications management - Leading and guiding

- Communications - Cultural and global effectiveness - Moral performance - Critical evaluation

- Business skills and intelligence

International Experiences in Competency Models

A: the workers' main competency field

Organizational Competency: The capacity to understand and internalize the organization's specific knowledge including the type of business, culture, policies, procedures, organizational goals and etc.

Social Competency: Basic abilities for social interaction and communications including relation building skills, maintaining interpersonal relations and enjoying social relations with coworkers.

Cognitive Competency: The ability to analytically learn and think, plan and solve problems that enable a person to accept the responsibility for events that occur.

Self-Competency (Self-adjusting): Ability to adjust with change, being prepared for learning and self-development, being prepared and ability to innovate and take actions, trust, tolerance, acceptance, mental extent and self-adjustment, self-respect, individuality and self-reliability

Job Competency: Capability, theory, methods and skills for doing job tasks, satisfying the self-efficacy need, selfconfidence regarding a specific job

B: Categorizing competencies based on visibility

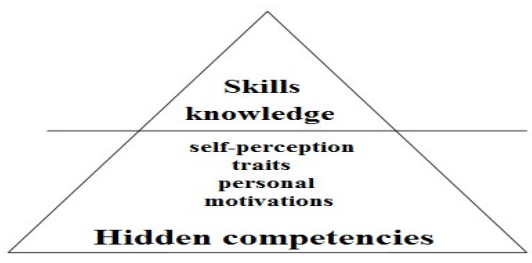

Figure 6: Iceberg Model

$\mathrm{C}$ : Categorizing competencies based on soft and hard skills

\begin{tabular}{|c|c|}
\hline Ultimate hard skills & $\begin{array}{c}\text { Hard skills } \\
\text { Using tools } \\
\text { Using texts and formula } \\
\text { Authority, Coordination } \\
\text { Tolerance } \\
\text { Planning, Preparation, Organizing, } \\
\text { Designing, Description, identification } \\
\text { Skill transfer, process development, } \\
\text { problem solving, attitude, tools } \\
\text { development } \\
\text { Capacity, timing, learning, creativity, } \\
\text { empathy and sympathy innovation, } \\
\text { aesthetics }\end{array}$ \\
\hline Ultimate soft skills & Soft skills \\
\hline
\end{tabular}

Figure 7: The Range of Hard and Soft Skills 
Indices of necessary competencies for supervisors of Iran's industrial oil and gas companies A: some of the criteria of management competencies of Iran's oil and gas companies

\begin{tabular}{|c|}
\hline Competency \\
\hline Judgment and decision-making \\
\hline Teamwork \\
\hline Communications \\
\hline Empowering and delegation of authority \\
\hline Leadership \\
\hline Technical skills \\
\hline Trust building \\
\hline Self-awareness \\
\hline Conflict management \\
\hline Time management \\
\hline Stress management \\
\hline Change management \\
\hline Innovation \\
\hline Planning and organizing \\
\hline Risk management \\
\hline
\end{tabular}

B: The design of sustainable competency-based human rresources management: A holistic approach

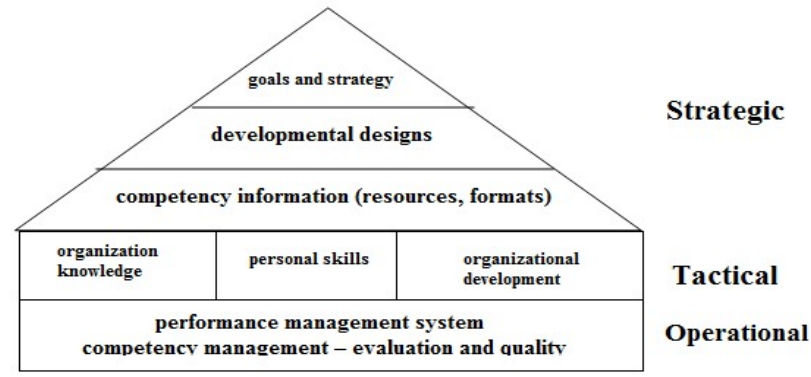

Figure 8: A Holistic View on Performance Management Process in an Organization

C: Key aspects of technology-based competency management include:

- defining long-term personal development goals

- defining learning goals to achieve competency

- ability to record, draw and trace competencies

Based on literature review and the survey from 15 experts, three stages of the Delphi method was arranged and, using statistical methods that were mentioned and will be explained later, the competency model of researchers was obtained and it was confirmed with a high ranking.

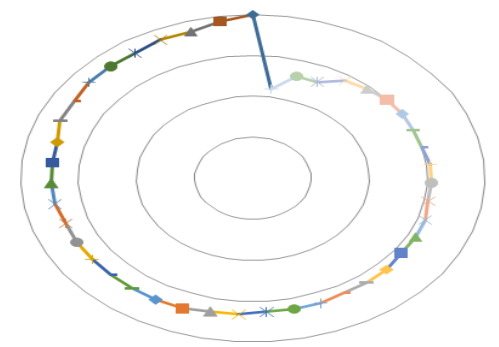

Figure 9: The Suggested Model and the Amount of its Confirmation

From top (clockwise): creativity and innovation - presence of women in the labor market - water crisis - financial management - analysis and using ICT - self-confidence - open mind approach/ mind development/ prospect knowledge - aural skills - negotiation skill and efficient relation - stress management - fossil energy replacements/changes transnational labor market - management and organization knowledge - sustainable development - capacity to evaluate others - developmental learning/ project's future of learning - enthusiasm/ motivating co-workers - risk management - 
business talent and entrepreneurial spirit - pragmatism - skills in communication - resources management - conflict management - formulating the research subject/ problem solving - regional turbulences - science and technology policies - capacity of decision-making about challenges - ability to do teamwork - leadership and project management - strategic thinking - time management - network development capacity - ability to be challenged - adjustability/ compatibility - skills in foreign languages - crisis management - decision-making - systematic thinking and planning skill - professional scientific knowledge - art of communication and influencing - responsiveness and customerism integration

Based on the model, competency report card has been designed for each person using the software.

\section{Results and Discussion}

Validity of the model was tested using Structural Equation Modelling by LISREL software.

\section{Confirmatory Factor Analysis}

The most important goal for confirmatory factor analysis is to determine the power amount of pre-defined factor model with a set of observed data. In other words, confirmatory factor analysis is looking to determine whether the number of factors and variable loads that were measured on these factors comply with what was expected from the theory and the theoretical model. In other words, this type of factor analysis tests the compliance and conformity between theoretical and experimental structures of the research. Therefore, one of the functions of confirmatory factor analysis is validity evaluation of the model.

In confirmatory factor analysis, the standardized loads are significantly important in interpreting factor analysis. These loads represent correlation between each observed variable and its related factor. The strength of a relation between the factor (hidden variable) and observable variable is shown by the factor load. If the factor load of an index in relation to a specific structure is bigger, that index will play a bigger role in explaining that structure. Also, if the factor load an index is negative, it shows its negative effect in explaining the related structure. In other words, the question related to that index has been reversely designed. Factor load is a value between 0 and 1 . If the factor load is smaller than 0.3 , the relation is considered weak and will not be considered. A factor load between 0.3 and 0.6 is acceptable. If the factor load is bigger than 0.6 , it is very desirable.

Factor analysis of knowledge structure

As it has been shown in Figure 9, the factor loads of all competencies of knowledge structure are at least in an acceptable. As it can be seen, the biggest factor load (0.83) belongs to financial management (q3).

In Figure 10 and since all the relations between variables and the structure (foresight and planning competencies) are bigger than 1.96, then all the relations are significant and thus, confirmed.

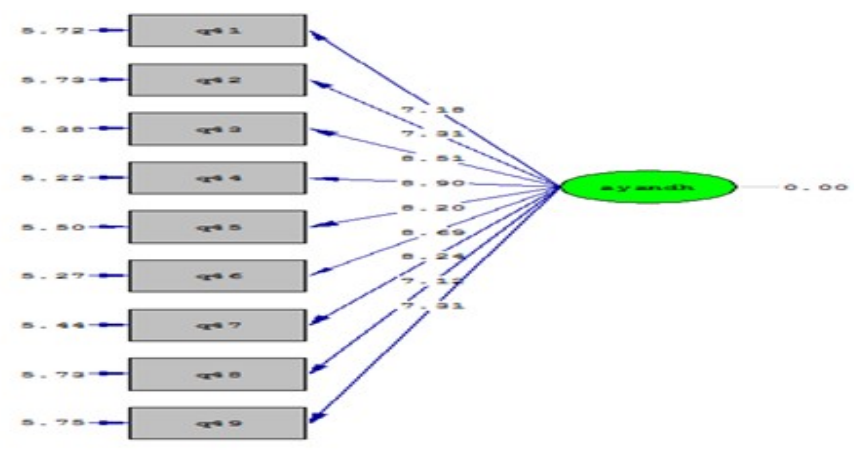

Figure 10: Factor Analysis of Foresight Structure (Significance Model)

\section{Second-time Factor Analysis}

First-time confirmatory factor analysis evaluates the relation between a factor or factors (hidden variables) and items (observable variables). In this method, the relation between hidden variables is not studied at all. This type of evaluation is merely to make sure that hidden variables have been measured accurately. In the first-time confirmatory factor analysis, the relation between a factor and several items or the relation between several factors and several items.

But when a big structure itself is consisted of several hidden variables, second-time factor analysis is used. In secondtime factor analysis, in addition to investigating the relation between visible and hidden variables, the relation between hidden variables and the main structure is studied as well. 


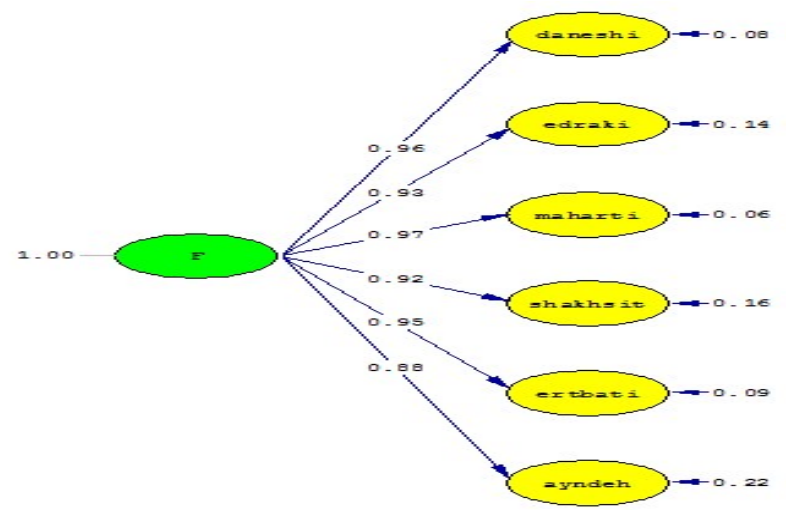

Figure 11: Second-time Factor Analysis (Standard Estimation Model)

As it is shown in Figure 11, the factor load of all the competency levels (6 levels) are in a desirable state, because all the factor loads are more than 0.70 . We can also see that the biggest load factor belongs to skill level (0.97).

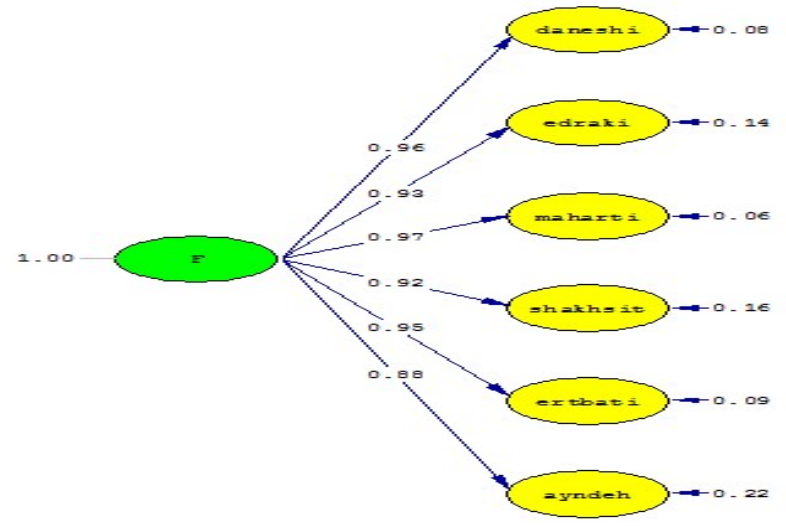

Figure 12: Second-time Factor Analysis (Standard Estimation Model)

In Figure 12 and since all the relations between competencies and research main structure are bigger than 1.96, all the relations are significant and thus, confirmed. Therefore, the validity of the research model structure is confirmed and in the end, the final competency model of researchers, shown below(Figure 13), was confirmed.

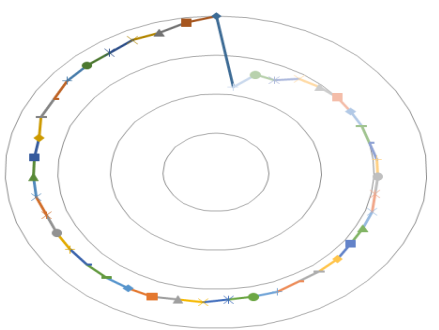

\section{Figure 13: Suggested Model and its Amount of Confirmation}

\section{Conclusion}

Many researches have been conducted on competencies for job and management positions in different organizations in Iran and in the world; but there has not been any study about strategic competencies of researchers and thus, the present study is considered as a new research. Carrying out confirmatory factor analysis on LISREL software, it was concluded that factor load of all competency components ( 6 components) are in a desirable state and all the factor loads are bigger that 0.70 and also all the relations between the competencies and research main structure are bigger than 1.96, which means that all the relations are significant and thus, confirmed. Therefore, the validity of research model structure was confirmed. It is noteworthy that no study had ever been conducted before to extract a local model for strategic competencies of researchers and therefore we can certainly claim that this research is the first in country about strategic competency model of researchers in oil industry research centers and in the Institute for International Energy Studies. 
In this section and by presenting some methodological points from the research, some suggestions are made for future researchers. We hope that by taking further research steps, more complete actions will be taken and we will achieve more findings.

The analysis level of the present study is at the level of research organizations and the Institute for International Energy Studies as the case study. Considering the difference between functional diversities of research organizations, we recommend that a similar study will be conducted in other research organizations. With this description, the final model of competencies might be different in each research organization. This study was conducted in the Institute for International Energy Studies, but similar studies in other research organizations are needed for generalization. This is as similar to the previous point which says model of strategic competencies might be different in other research institutes. Number of competencies extracted by the researcher is too much and we recommend to take fewer core competencies into account in future studies and instead we suggest increasing the quality of extracting methods of competency development. One of the serious objections to the model of competencies is relation identification between dimensions and components of competencies; however, considering the definition of competency model in this study, this point is unrelated. Therefore we suggest that in future studies, the relation between competencies gets investigated in the competencies model. Some of the competencies are considered as basic and potential abilities and some are indicators and results of having another competency (for instance, the competency of open mindedness is a core competency for the competency of understanding strategic thinking.). This being said, future studies should try to consider this approach in designing their competency model. In order to extract strategic competencies of researchers and even key competencies of occupations and management, it is better to use combined methods and not be content with seeminglyvalid methods. For example, future studies can use strategies of field observation, conduct a deep interview with the highest responsible person in the organization, analyze the process of HR management in the organization, investigate the organizational maturity level using common models, carefully study strategies and goals of the organization.

Questionnaire is a common tool in collecting information is widely used in most management and behavioral studies. But this tool is not that efficient in extracting competencies models and even in extracting methods of competency development and therefore we advise using qualitative approaches in this kind of researches. A focus group consisted of expert physicists can appropriately consider different aspects of extracting components and dimensions in a relatively long time. Identifying competencies is a very important issue and understanding how to develop these competencies is an issue different from designing a competency model. For future researchers, we recommend that a deep study should be conducted on one competency and one superior and more efficient method to develop that competency; and that study should move towards implementing that method or methods in a more organized manner. One of the deficiencies of the present study is identifying a group of methods for developing strategic competency of researchers. Thus, for improving each competency or similar competencies or even components of competencies, we advise future researchers to select a method and conduct a deep study on it. The present study only tried to identify strategic competency of researchers and has not paid attention to consequences, problems and establishment issues and methods implementation. Therefore, we advise future researchers to study the problems regarding implementing methods of developing strategic competencies of researchers. The current study has investigated HR competencies for researchers in a general/not technical section that can include organizational competencies.

\section{References}

1. Behzad Abolalayee \& Abbas Ghaffari (2009); Human asset: competitive advantage of organizations in the field of globalization; selection of articles from $37^{\text {th }}$ conference of human resources; Saramad Publications; $1^{\text {st }}$ edition

2. Thomas H. Davenport; Thinking for a Living: How to Get Better Performances and Results from Knowledge Workers; Translated by Gholamreza Asili, Tehran; Publications of Petroleum Industry Research Institute

3. Study group of faculty of strategic management; production of science and technology (principles and strategies); Publications of National Defense University

4. Gholamhossein Rezayat, Mohammad Yamani Douzi Sorkhabi, Alireza Kiamanesh \& Abdlrahim Naveh Ebrahim (2011); Architecture of Competency Models: Presenting a Conceptual Framework; HR Management Researches; $3^{\text {rd }}$ year, $2^{\text {nd }}$ issue; pages $49-81$

5. Strategic document of HR development in Petroleum industry; the Institute for International Energy Studies; 2010

6. Rahmatallah Gholipour \& Ebrahim Gholampour; Process of public policy-making in Iran; Publications of Islamic Consultative Assembly Research Center; 2010

7. Mohammad Bagherizade; How does science evolve and grow? (2014)

8. Management Department of Management United Nations. URL: https://hr.un.org/sites/hr.un.org/files/Un_competency_development_guide.pdf. November,1999

9. Hioner Company (1998); Efficiency of Organizations and Research Units; Translated by Alireza Boushehri \&Aghil Malekifar; Publications of Defence Industry Research and Education Center; $1^{\text {st }}$ edition

10. Mahdi Afkhami Ardakani, Jabar Babashahi, Hamidreza Yazdani, Reza Tahmasbi (2016); Presenting tools for identification and evaluation of knowledge-based and research-based occupations with a mixed approach; Journal of HR Management Researches 
11. Hamed Dehghanan; Competency-Based Management; Journal of Council and Research; $13^{\text {th }}$ year, issue no. 53; Publications of Islamic Consultative Assembly Research Center; 2007

12. Agut S. \& Grau R. (2002) Managerial competency needs and training Requests: The case of Spanish tourist industry, Human Resource Development Quarterly, 13 (1) 31-51.

13. Cizel, B., Anafarta, N., \& Sarvan, F. (2007). An analysis of managerial competency needs in the tourism sector: The case of Turkey. Tourism Review,62(2), 14-22

14. Richard E. Boyatzis, (2009) "Competencies as a behavioral approach to emotional intelligence", Journal of Management Development, Vol. 28 Issue: 9, pp.749-770, https://doi.org/10.1108/02621710910987647

15. P. Torres, M. Augusto, The Impact of Experiential Learning on Managers' Strategic Competencies and Decision Style, Proceedings of 2016 Global Innovation and Knowledge Academy (GIKA 2016) Conference, 10, Valencia, Espanha , 2016

16. Loufrani-Fedida S., Missonier S.,2015,The project manager cannot be a hero anymore! Understanding critical competencies in project-based organizations from a multilevel approach, International Journal of Project Management, 33 (6).

17. Ennis, M. R. (2008). Competency models: a review of the literature and the role of the employment and training administration (ETA). US. Department of Labor.

18. Global Challenges - C. Glenn, Jerome et al - Future condition; 2008; Publications of Amirkabir University Tehran; $1^{\text {st }}$ edition

19. Jabbar Babashahi et al - 360 Degree Evaluation of Staff and Managers of Petroleum Industry Exploration Management; Institute of International Energy Studies: 2017

20. Society for human resource management (SHRM) 2012

21. NaliniDevi.S et al. American International Journal of Research in Humanities, Arts and Social Sciences, 3(2), June-, 2013, pp. 168-170.

22. The design of sustainable competency Based human Resources management : A Holistic Approach, Fanny Klett, Knowledge management \& E- Learning 2017 